\title{
Collaborations on the Edge
}

\section{Katharina Rohde}

Department of Architecture, Katholieke Universiteit Leuven, Leuven 3001, Belgium; me@katharina-rohde.com Received: 7 July 2017; Accepted: 27 July 2017; Published: 7 August 2017

\section{Introduction}

Since 2005 I have been working with mobile communities in the cities of Berlin, Germany and Johannesburg, South Africa. The two cities differ in many aspects but also share similarities. They both have histories of division but also great diversity, which while challenging can also provide the opportunity for the evolution of truly pluralist spaces and communities of citizens and non-citizens. It is in this context that the present project emerged, to encourage points of contact between non/citizens and to imagine future spaces, that host a multiplicity of voices and interests.

\section{Urban Appetite (Johannesburg, 2005)}

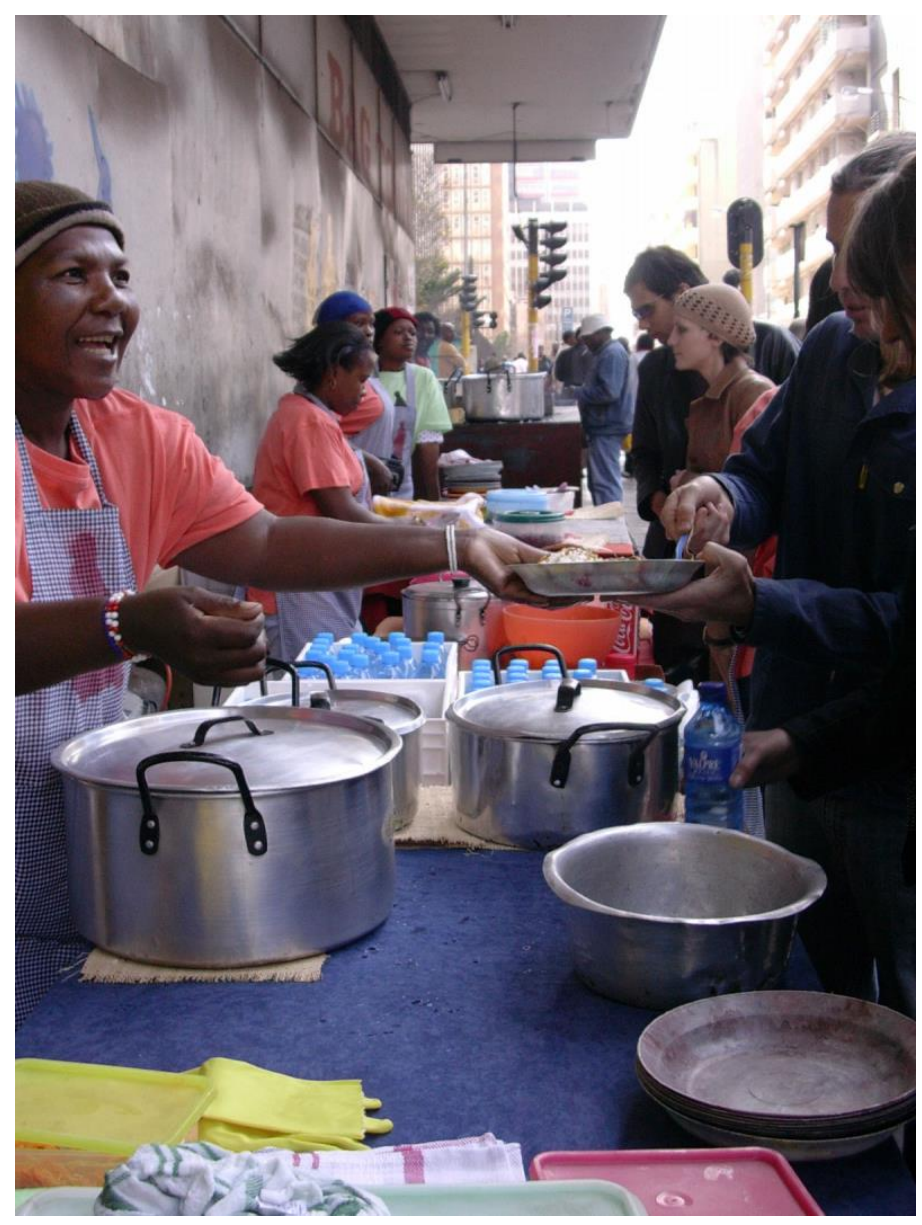




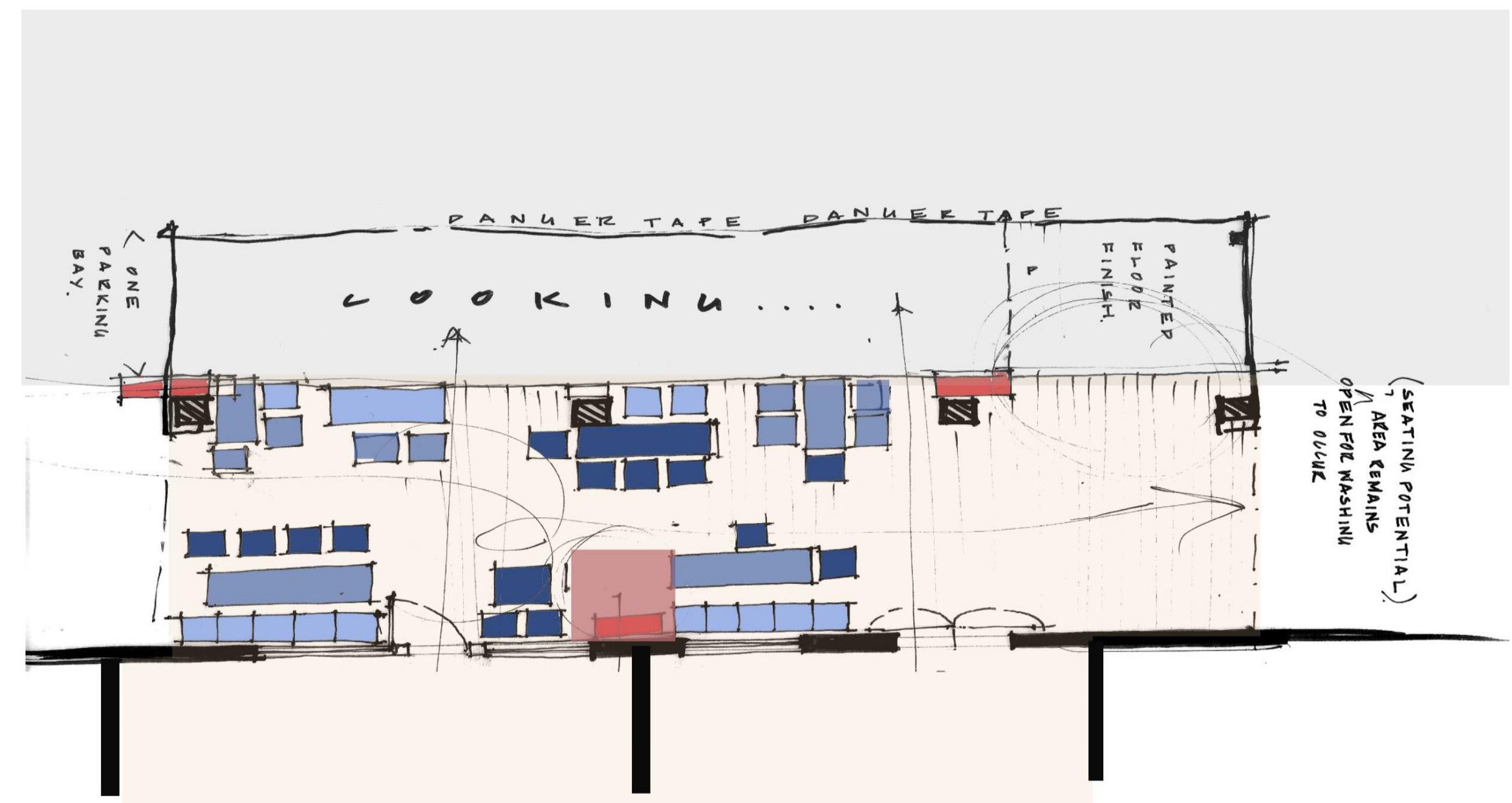


The Urban Design studio-Urban Fabrics—looked at the agency of street traders: in finding space within a dense and highly competitive inner city context; in inventing businesses as a mode of survival; in creating social networks of support. Working together with the studio, the aim was to propose possible solutions that could be incorporated into the future development of the area.

Urban Appetite brought together immigrant street cooks and organized a street restaurant that would respond to the different conditions and needs in the course of a day. During peak business hours, the restaurant's set up allowed for the fluid accessibility of the pavement, and 'Food on the Move' was invented for business-wo/men on their way. While during off-peak, the restaurant extended its space for customers to enjoy a relaxing meal.

This pop-up street restaurant was a collaboration with street traders from different African countries seeking refuge in Johannesburg. Students and invited customers were largely new to this downtown area as it was-and partly still is-perceived as a no-go zone. The restaurant, therefore, triggered discussions around under-explored parts of the city and its makers-who are, to a great extent, displaced people from countries such as Malawi, Zimbabwe, The Democratic Republic of Congo.

A series of actions evolved during the course of an urban design studio held at The School of Architecture and Urban Planning of the University of the Witwatersrand in 2005. Urban Fabrics was set up in the context of ongoing urban regeneration of the fashion district, in downtown Johannesburg, and the threat of street traders being displaced.

(Note: this is the subtext for above project)

Collaborators: Hannah Le Roux, The JDA (Johannesburg Development Agency) 
The Expandable Fight (Johannesburg, 2010)

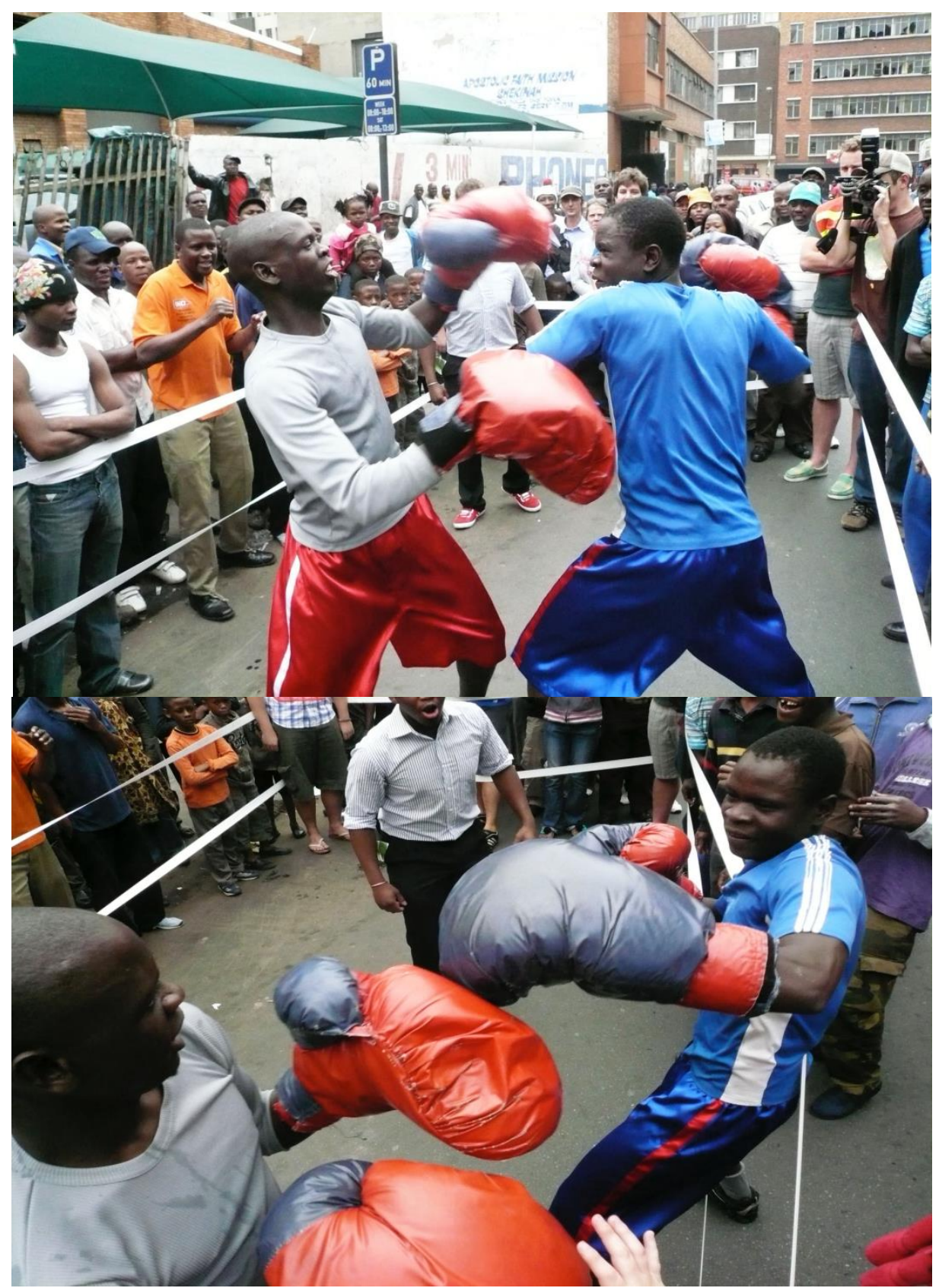

Photos: Katharina Rohde.

The performance, the 'Expandable Fight' evolved during the build up to the FIFA World-cup in South Africa in 2010, when street traders in the inner city of Johannesburg faced evictions on a daily basis:

Two street traders in a boxing contest in downtown Johannesburg. The space is delimited by an elastic ribbon, which becomes narrower and narrower with each round. The project tackles issues of survivalist strategies amongst displaced people on the street level; the daily struggle for space and goods, facing competition, spatial regulations and harsh law enforcement. 
This performance was developed during an Art and Activism studio that took place at the School of Arts of the University of the Witwatersrand. The studio was part of the Pavement Economies-The Happy Hawker project that developed in 2009 with the support of the Goethe Institute, South Africa.

Collaborators: Lindy Scott, Jo Voysey.

\section{How We Live Together (Berlin, 2015/16)}

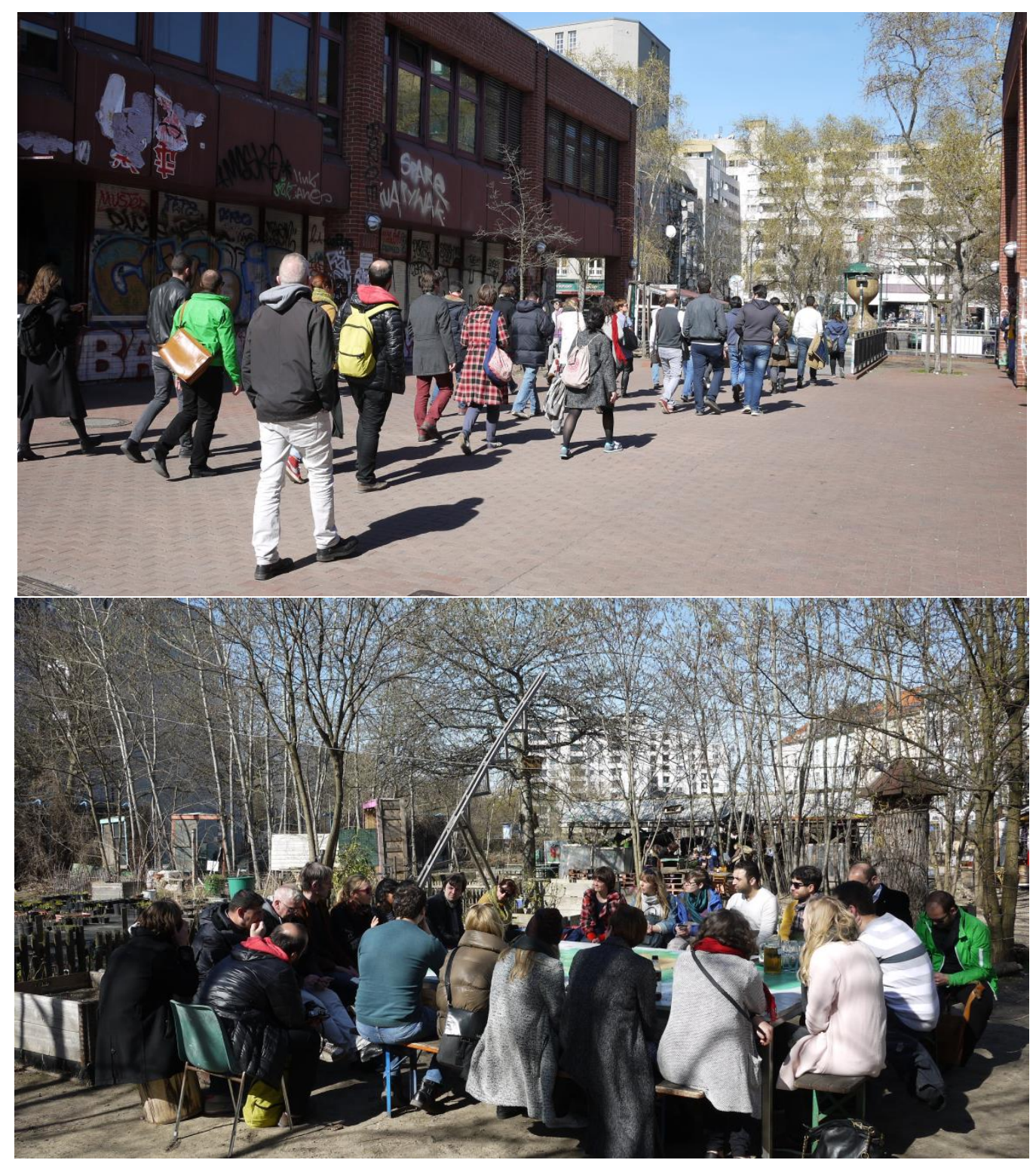

Photos: Ingrid Sabatier.

The (relatively) high influx of people to Berlin in 2015 resulted in an administrative crisis in the city and led to a mushrooming of projects and volunteer initiatives in order to welcome and support the newcomers.

'How We Live Together' used urban walks as a method to initiate encounters between people newly arrived in Berlin and urban actors familiar with the city. The collective walks triggered discussions around space-making and possible futures for a pluralist city to emerge, while simultaneously providing an introduction to the manifold neighborhoods. It further served as a networking tool to build friendships, support systems and work opportunities. 
The Urban Walks were a collaboration of Katharina Rohde, Ingrid Sabatier \& Stephan Schwarz (ISSS architecture and research) and The German Architecture Centre (daz).

\section{Immediate Housing—Sustainable Neighborhood}

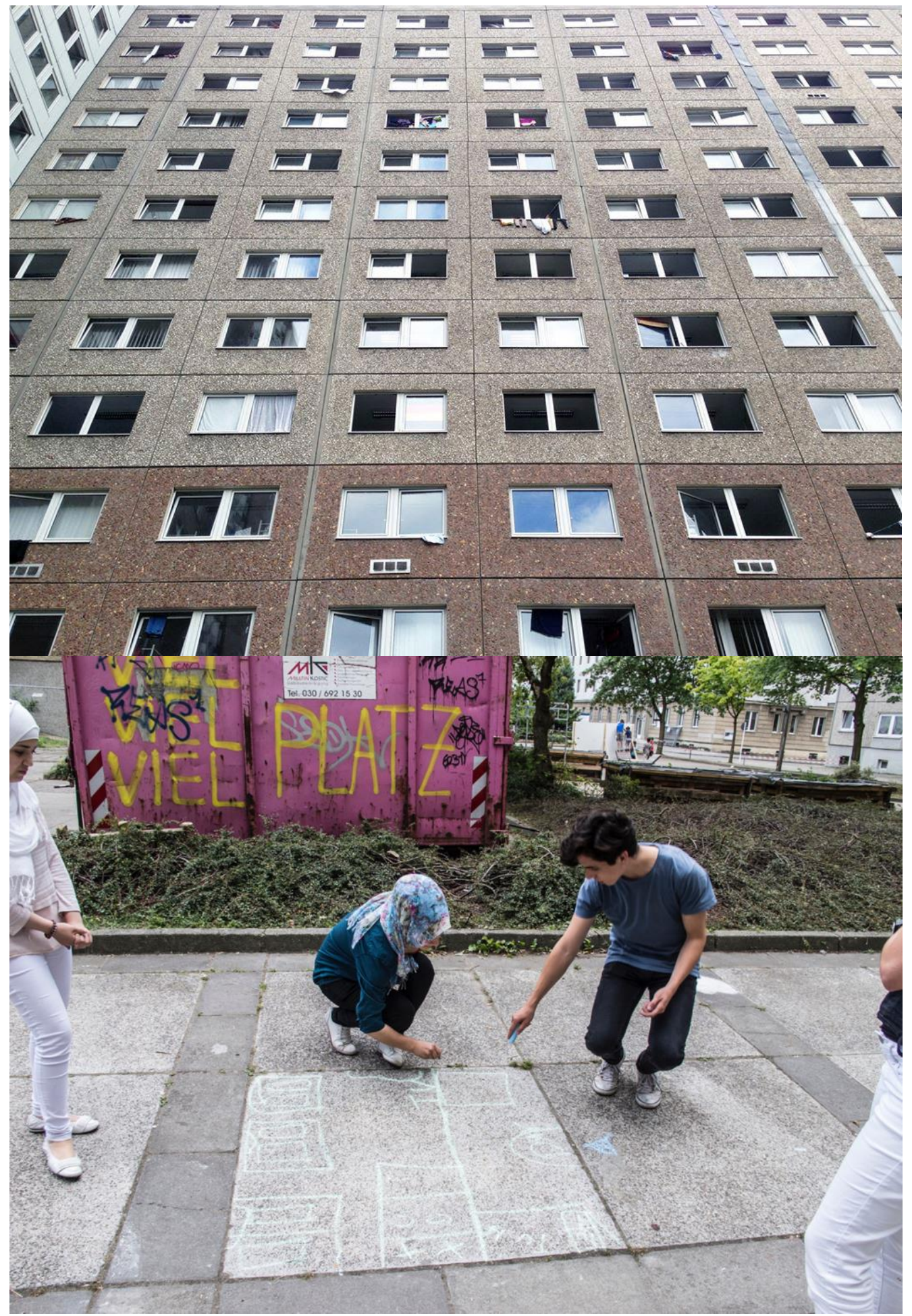

Photos: Kaja Kuehl. 
During a 10 day summer school students of architecture and urban design from Berlin, New York and Brussels were asked to develop convincing concepts for housing that can be built fast, and become an integral part of the neighborhood in the long run. Engaging with newcomers, hosted in an emergency shelter within the former state-security (Stasi) headquarters, provided input for negotiating a balance between shared and private spaces, between off-site and on-site construction and for thinking about integration as interaction. The projects also sought to integrate retail and service providers that offered opportunities for newcomers while also creating vibrant urban spaces in the neighborhood. All the student projects which responded to this idea suggested that housing should not be limited to newcomers, even in the initial phase, but should welcome a variety of residents.

The Summerschool was a collaboration of Kaja Kuehl (GSAPP, Columbia University New York), Katharina Rohde (KU Leuven) and Oliver von Spreckelsen (UdK Berlin) and supported by the housing company HOWOGE.

Conflicts of Interest: The author declares no conflict of interest.

(C) 2017 by the author. Licensee MDPI, Basel, Switzerland. This article is an open access article distributed under the terms and conditions of the Creative Commons Attribution (CC BY) license (http://creativecommons.org/licenses/by/4.0/). 